\title{
Domestic hot water consumption vs. solar thermal energy storage: The optimum size of the storage tank
}

\author{
M.C. Rodríguez-Hidalgo ，P.A. Rodríguez-Aumente , A. Lecuona ， M. Legrand ， R. Ventas
}

\begin{abstract}
A B S T R A C T
Many efforts have been made in order to adequate the production of a solar thermal collector field to the consumption of domestic hot water of the inhabitants of a building. In that sense, much has been achieved in different domains: research agencies, government policies and manufacturers. However, most of the design rules of the solar plants are based on steady state models, whereas solar irradiance, consumption and thermal accumulation are inherently transient processes. As a result of this lack of physical accuracy, thermal storage tanks are sometimes left to be as large as the designer decides without any aforementioned precise recommendation. This can be a problem if solar thermal systems are meant to be implemented in nowadays buildings, where there is a shortage of space. In addition to that, an excessive storage volume could not result more efficient in many residential applications, but costly, extreme in space consumption and in some cases too heavy.

A proprietary transient simulation program has been developed and validated with a detailed measurement campaign in an experimental facility. In situ environmental data have been obtained through a whole year of operation. They have been gathered at intervals of 10 min for a solar plant of $50 \mathrm{~m}^{2}$ with a storage tank of $3 \mathrm{~m}^{3}$, including the equipment for domestic hot water production of a typical apartment building.

This program has been used to obtain the design and dimensioning criteria of DHW solar plants under daily transient conditions throughout a year and more specifically the size of the storage tank for a multi storey apartment building.

Comparison of the simulation results with the current Spanish regulation applicable, "Código Técnico de la Edificación" (CTE 2006), offers fruitful details and establishes solar facilities dimensioning criteria.
\end{abstract}

\section{Introduction}

Domestic hot water (DHW) consumption is strongly variable. It depends on the geographical situation, also on the people habits, on the time of the year, and of course on the type of building usage. Above all, it depends on the inhabitants' specific lifestyle [1-9].

Following the Directive 2002/91/EC of the European Parliament and of the Council of December 16th 2002 on the Energy Performance of Buildings, (EPBD) [10] the different countries have transposed it in new national regulations such as: "Código Técnico de la Edificación (CTE 2006)" [11] in Spain. There, an estimation of the mean hot water consumption is offered, in similar terms as in the Italian code "UNI/TS 11300 2008" [12]. Nevertheless, residential DHW consumption might show diverse daily consumption profiles at a standard temperature, depending on the inhabitants' demands along the week $[4,6]$. The user mixing with fresh tap water obtains the final temperature. Consequently, the instant thermal energy needed to heat the water should be supplied at a different pace throughout the day, and therefore the heat source that would be needed to supply the instant demand has to be oversize, which would lead to low values of efficiency [13].

All these facts indicates the convenience of storing DHW in tanks in order to have water prepared for consumption at the desirable temperature whenever inhabitants require it [13].

The plant design turns into a straightforward work in case the heat source is a boiler. Designers could relate both the nominal heat power of the boiler and the storage volume to the time period needed to increase the temperature of water to the standard value; this one is established in order to prevent legionella disease. In Spain this value is of $60^{\circ} \mathrm{C}$ throughout $2 \mathrm{~h}$ every day as a minimum time period $[4,11]$.

When the DHW is heated by a solar thermal plant, storage is mandatory in residential buildings, as usually the consumption is not coupled with the solar irradiation daily profile. The thermal 


\section{Nomenclature}

A collector field absorber area $\left(\mathrm{m}^{2}\right)$

$a_{0} \quad$ optical collector efficiency (-)

$a_{1} \quad$ collector thermal loss coefficient $\left(\mathrm{W} \mathrm{m}^{-2} \mathrm{~K}^{-1}\right)$

$a_{2} \quad$ collector thermal loss coefficient $\left(\mathrm{W} \mathrm{m}^{-2} \mathrm{~K}^{-2}\right)$

c specific heat $\left(\mathrm{J} \mathrm{kg}^{-1} \mathrm{~K}^{-1}\right)$

D diameter $(\mathrm{m})$

DHW domestic hot water

$G \quad$ solar irradiance $\left(\mathrm{W} \mathrm{m}^{-2}\right)$

$m \quad$ mass $(\mathrm{kg})$

Q instantaneous thermal energy output (W)

$T$ temperature (K)

$t \quad$ time (s)

UA thermal loss coefficient of the storage tank $\left(\mathrm{W} \mathrm{K}^{-1}\right)$

$V \quad$ storage tank volume $\left(\mathrm{m}^{3}\right)$

$Z \quad$ storage tank node height $(\mathrm{m})$

Subscripts

a ambient c transversal net water flow

co related to collector

$i \quad$ storage tank node

in input

j collector component

local room where the storage tank is located

loss thermal loss

$m \quad$ mean value between inlet and outlet

out output

solar related to the sun

$T \quad$ sloped surface

Greeks

$\lambda \quad$ water empirical equivalent conductivity parameter ( $\mathrm{W} \mathrm{m} \mathrm{m}^{-1} \mathrm{~K}^{-1}$ )

collector efficiency $(-)$ energy gathered by the collector field is stored in an insulated water tank. As solar irradiance will not always be enough to raise the water temperature up to $60^{\circ} \mathrm{C}$ an auxiliary boiler completes the plant; typically this boiler is driven by natural gas.

In CTE [11] the minimum solar fraction, i.e. the minimum DHW consumption that must be covered with solar thermal energy is established, depending on the incident solar irradiation in the location and on the total DHW consumption of the building.

Both collector and storage tank are individually subjected to European standards, EN 12975-2 [14] and EN 12977-3 [15] where their performances, like thermal loss and stratification, are evaluated under established environmental and working conditions.

Open literature shows a large number of studies where solar plant performance is described by means of experimental data, e.g. [16-18], or by simulation programs [19-36], among others.

In order to dimension thermal solar plants, there are simplified methods, such as f-Chart $[37,38]$, that help designers to estimate the adequate collector area. On the contrary, the size of the storage tank is left to the designer choice. Only few recommendations appear in legal documents, such as in CTE [11], where vertical storage tanks are recommended as they favour thermal stratification $[11,15,39]$. The recommended ratio between storage tank volume and collector field area is given in CTE by

$$
0.05 \mathrm{~m} \leqslant V / A \leqslant 0.18 \mathrm{~m}
$$

Transient simulation programs, typically based on TRNSYS [40], as recommended in EN 12977-2 standard [15], need as input data the storage tank volume $V$ and the collector field absorber area $A$ among other variables, and as a result, the solar fraction is given. This way no other optimizing process than a try and error procedure can be performed when designing a solar plant.

Fig. 1 shows a simplified scheme of the DHW solar facility studied in this paper. As this paper shows, the storage volume not only affects the accumulated energy but also the heat exchanger and collector performances. In consequence, its size will influence in a significant way the performance of the whole DHW solar plant.

In the present work, a transient model for the whole DHW system has been developed. Once experimentally validated, the model is used to obtain the design and dimensioning criteria of DHW solar plants and more specifically, for an apartment building.

The previously mentioned simulation programs use hourly synthetic environmental data, although they can use a smaller time step in their calculations interpolating the values of the hourly interval. The developed model uses experimental instantaneous environmental data, measured each $2 \mathrm{~s}$ and the mean value is recorded each $10 \mathrm{~min}$. This smaller sampling time allows describing more accurately the real environmental data evolution throughout the day, and therefore the solar facility components performances and their dynamic response.

\section{Main components of DHW solar plants (a custom built system), types and prices}

The collector field is usually considered one of the most expensive components of the solar plant. The commercial types used for DHW solar plants are flat plate, flat plate of high efficiency, vacuum tubes and heat pipe collectors, like in [41] for a multipurpose application. The suitability of each type is related to the application, and the value of the normalization efficiency parameters $a_{0}, a_{1}$, and $a_{2}$ are obtained from the EN 12975-2 test [14]. Eq. (2) shows the normalization efficiency curve [14], obtained under specified ambient and operating conditions. It is shown here only for informative purposes.

$\eta=a_{0}-a_{1}\left(\frac{T_{m}-T_{a}}{G_{T}}\right)-a_{2} G_{T}\left(\frac{T_{m}-T_{a}}{G_{T}}\right)^{2}$

The $a_{0}$ parameter indicates the optical efficiency of the collector; this way, the higher it can be the most efficient the collector is. $a_{1}$ and $a_{2}$ are the thermal loss parameters, the lower their values are the less thermal loss the collector presents. In Fig. 2, the $a_{2}$ efficiency parameter is disregarded as its influence on the result is small for the present argument. The studied collector's configurations are: covered flat plate, high efficiency flat plate excluding double glass cover, vacuum tubes and heat pipes.

As seen in Fig. 2, the most expensive collectors are the vacuum tubes; they offer higher values of $a_{0}$ and the lowest values of $a_{1}$. The heat pipe collectors are a variant of the vacuum tubes; they share these characteristics but with the drawback that $a_{1}$ is higher. Flat plate collectors, as used in the present work, exhibit high values of $a_{0}$ at a relatively low cost, but with the drawback that $a_{1}$ is also important. These attributes make them suitable for low temperature applications, such as DHW, up to mid-high latitudes. For the same collector type, the higher the $a_{0}$ value is the collector price increases, but the value of $a_{1}$ remains sensibly constant. This 


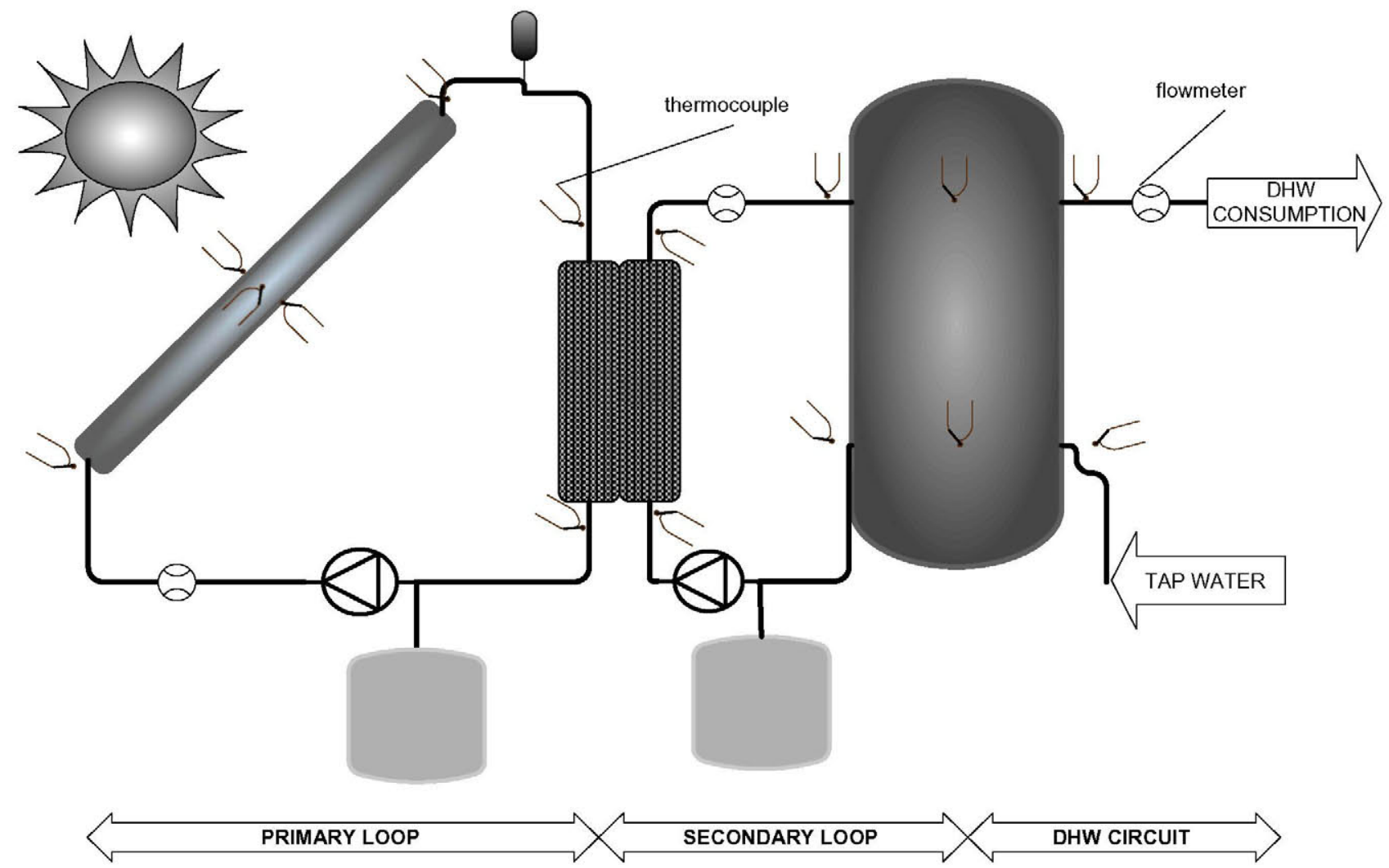

Fig. 1. Solar plant diagram. Instrumentation is indicated.

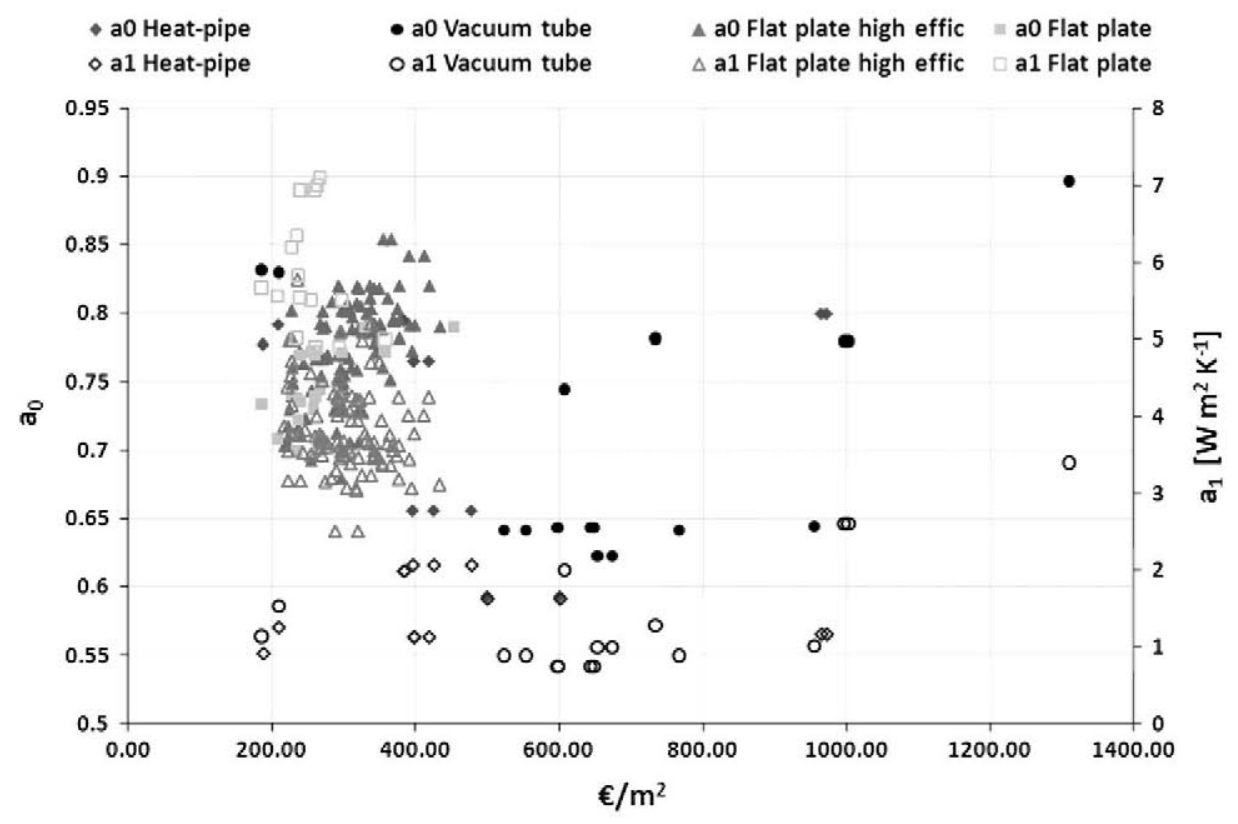

Fig. 2. Collector efficiency normalization parameters and prices. Data correspond to 2009 for the $90 \%$ thermal collector manufacturers operating in Spain.

fact shows up that collector price for the studied configurations seems to be more related to improvements in optical properties than in thermal insulation.

Within the scope of this paper, commercial water storage tanks can be divided into two types, depending on the existence of a heat exchanger coil inside them or not.

Apart from the previous classification, they can be further classified depending on the material they are made of: stainless steel, vitrified steel and steel with an epoxy coating, all of them being suitable for contact with drinking water, essential in DHW circuit (see Fig. 1). Typically, storage tank size ranges from $0.1 \mathrm{~m}^{3}$ to $5 \mathrm{~m}^{3}$, as they need to cover the DHW consumption of the inhabitants of the different size of buildings.

Fig. 3 offers a summary of a market research performed on water storage tanks. The manufacturers' data used represent about $90 \%$ of the market share in Spain. The stainless steel storage tanks 


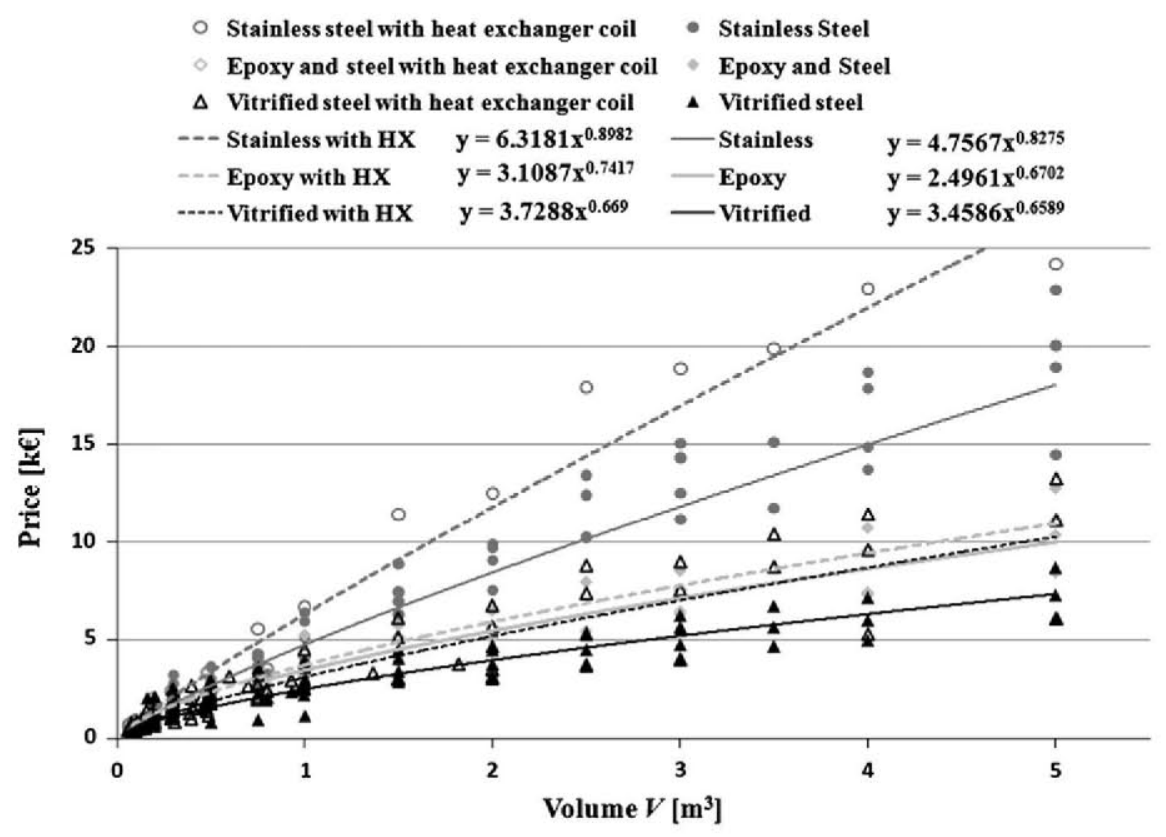

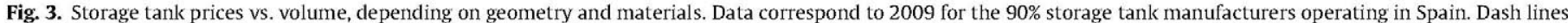
correspond to the storage tank with heat exchanger coil; continuous lines correspond to storage tank without it.

turn out to be the most expensive. They are followed by the epoxy coated steel tanks. The cheapest storage tanks are the vitrified steel ones. As an example, using flat plate collectors for DHW and selecting a value of $V / A=0.1 \mathrm{~m}$, the estimated cost of the collector field and of the thermal storage tank are quite similar. This is $15,000 €$ for each one, being the collector field composed of $50 \mathrm{~m}^{2}$ flat plate collectors and the storage tank being of $5 \mathrm{~m}^{3}$, of the vitrified steel type with heat exchanger coil.

This means that not only the collector field cost and the needed roof space represent the key factors for the inhabitants when deciding to install or not a solar plant for DHW supply. The price of the storage tank, together with the space needed to place it inside the building, are also relevant, not to mention difficulties in door access for the tank placement.

\section{Experimental solar plant and model description}

The experimental plant consists of a 9 years-old flat plate thermal collectors field (at around half its expected operational life), with a total absorbing area of $50 \mathrm{~m}^{2}$, placed on the four storey building horizontal terrace in four rows of $6,6,5$ and 3 collectors each. They are oriented to the south, with a surface azimuth angle of $11^{\circ}$ east and $40^{\circ}$ sloped, which corresponds to the local latitude of Madrid, Spain. Water-antifreeze mixture (for winter operation) is pumped from an external plate heat exchanger to the collectors in a closed loop (see Fig. 1). Drinking water is pumped from the $3 \mathrm{~m}^{3}$ capacity storage tank, which is located on the cellar, through the other side of the plate heat exchanger, where it is heated and sent to consumption when required. Refs. [42,46] offer detailed information on the solar plant.

The thermal plant includes a meteorological station which records solar irradiance on horizontal and on a $40^{\circ}$ sloped planes, air temperature and pressure, wind direction and velocity, as well as relative humidity.

The time period studied covers a whole year operation, ranging from 2008-02-27 to 2009-02-26 and the time step used for data recording is $10 \mathrm{~min}$. The meteorological parameters of this year fall into the typical range values of the climatic zone studied.
All the relevant inlet and outlet temperatures of each component, together with the different fluid flow rates, have been instrumented using thermocouples type $\mathrm{T}$ and electromagnetic flow-meters, as shown in Fig. 1. Two thermocouples on the vertical axis inside the storage tank allow describing its stratification, which are depicted in Fig. 1. The whole instrumentation has been calibrated once installed in the plant with the aim to reduce the possible measurement errors.

The developed numerical simulation consists in a standalone transient model for each component, that is: solar thermal collectors, heat exchanger and storage tank. It is implemented in EES [47].

The instantaneous experimental temperature data of the collector absorber plate, glass cover and box back surface, together with the dimensions and properties of its components, led to the calculation of the convective and radiative thermal resistances and capacitances (product of mass by specific heat) of the collectors. This allowed validating the actual transient performances beyond the limited value of the normalization curve, Eq. (2) and the remaining EN 12975-2 standard [43,48]. The collector model uses a circuit of variable thermal resistances and capacitances to describe the collector transient performance, allowing the determination of their instantaneous and global thermal losses [43]. The solar field model can be summarized by Eq. (3), as follows:

$\sum_{j} m_{j} c_{j} \frac{d T_{j}}{d t}=Q_{\text {solar }}-Q_{\text {out }_{c o}}-Q_{\text {loss } c o_{c o}}$

where

$Q_{\text {solar }}=G_{c o} A$

$Q_{\text {out }}=m c\left(T_{\text {out }}=T_{\text {in }}\right)$

The $Q_{\text {loss }}$ is the heat loss of the collector field and this term has not a simple equation as the rest of the terms in Eq. (3), [43,48] offer a detailed description of the collector model.

Regarding the plate heat exchanger model, equations for mass and energy transient balances in a differential analysis are solved for the calculation of the temperatures and the heat flows inside 
it [46]. The methodology follows the log mean temperature difference procedure, but thermal losses and inertia contributions are evaluated for both flows in the heat exchanger and included in the above mentioned balance equations. Correction terms for the $\log$ mean temperature difference due to thermal losses and inertia are then obtained and implemented in the model [51].

The storage tank model is based on a finite volume method for the simulation of the storage tank performance, considering stratification. The storage tank model divides it into five similar finite volumes, vertically stacked. A generic $i$ node energy balance is summarized by Eq. (6), in the following fashion:

$$
\begin{aligned}
m_{i} c \frac{d T_{i}}{d t}= & \dot{m}_{\text {in }_{i}} c T_{\text {in }_{i}}-\dot{m}_{\text {out }_{i}} c T_{\text {out }}-Q_{\text {loss }_{i}}+\left(Q_{i-1, i}-Q_{i, i}+1\right) \\
& +\dot{m}_{c_{i}} c\left(T_{i-1}-T_{i}\right)
\end{aligned}
$$

where

$Q_{\text {loss }}=U A_{i}\left(T_{i}-T_{\text {local }}\right)$

$Q_{i-1, i}=\frac{\pi D^{2}}{4} \frac{\lambda}{Z}\left(T_{i-1}-T_{i}\right)$

$Q_{i, i+1}=\frac{\pi D^{2}}{4} \frac{\lambda}{Z}\left(T_{i}-T_{i+1}\right)$

Eq. (7) represents the thermal loss to the room ambience. The effective heat transfer is modelled as a conduction-like heat transfer, but taking into account this heat transfer between the ith node and its neighbours, bellow it with Eq. (8) and above it with Eq. (9) [49].

Each component subroutine uses, as input data, the outlet temperature of the upstream component together with the rest of the parameters and the variables needed to describe a single component performance beginning from the collector and finishing with the storage tank. Experimental instantaneous wind velocity and direction, ambient temperature and sloped solar irradiance, together with the effective sky temperature (obtained according to [44]) are also incorporated as inputs into the model, as it has been described in $[43,48]$.

These individual component subroutines are linked in order to predict the instantaneous thermal output of the solar plant. Once the transient model of each component is experimentally validated, all of them have been integrated in a unique programme. This allows obtaining a transient model able to describe the whole solar plant performance having as inputs the radiation and environmental data, as well as the instantaneous DHW demand and flow rates. This global model has also been validated experimentally with the plant operational data $[46,50]$.

As an example corresponding to a representative sunny and a cloudy day, Fig. 4 shows the experimental and model results. Incident solar power represents the higher magnitude, followed by the collector power output and followed by the power that is sent to the DHW consumption from the storage tank.

The DHW demand flow rate through the storage tank has been established with a constant value throughout the day from 7:00 to 22:00 local hours; this way the storage tank internal water motions due to the convection forces could be easily controlled without interferences from heavy discharges. This kind of control leads to a DHW temperature delivery variable throughout the day.

The consumption power profile obtained this way results to be similar to the one demanded by the studied apartment building, supplied at a constant temperature of $60^{\circ} \mathrm{C}$ and a variable water flow throughout the day, as Fig. 5 shows, which is the usually considered profile in simulation programs. The dispersion on the individual habits of the apartment building inhabitants' smoothes the instantaneous peaks of the DHW demand throughout the day shown in Fig. 5. This effect was studied in [45], giving a total power distribution (Q DHW) similar to the one shown in Fig. 4.

As can be seen in Fig. 4, the model results follow with great accuracy the experimental results obtained from the direct application of the temperatures and flow rates measured.

The 366 days have been studied the same way as the day 2008 09-14. An error analysis shows that the relative mean value of the difference between experimental and model results corresponds to $(+2.2 \pm 9.4) \%$ for the accumulated daily energy output from collectors and $(+10.0 \pm 19.3) \%$ for the accumulated daily energy employed in DHW, both calculations being performed throughout the whole year. The dispersion shown corresponds to a confidence interval of $95 \%$. The daily annual average accumulated energy that this solar plant produces is of $585.5 \mathrm{MJ}$.

\section{Model application: finding the optimal storage tank size}

Once the model is validated, the thermal storage size and consequently its heat loss have been modified for optimization, searching for the minimum size that fulfils the minimum solar fraction established in CTE, for the Madrid location solar irradiation.

In order to avoid crowding, only a representative day of each month has been selected for plotting. These 12 days correspond to the mean value of each month in terms of the instantaneous solar irradiance. This mean value has been obtained using the solar irradiance measured throughout the 9 years of operation of the meteorological station located $6 \mathrm{~m}$ above the collector field.

Following the indications explained in CTE, the DHW demand at $60^{\circ} \mathrm{C}$ of apartment building housings arrives to $0.022 \mathrm{~m}^{3}$ per person and day. Depending on the average daily solar irradiation, CTE shows a classification of the different zones in Spain. Madrid belongs to the IV zone, where the global annual average daily solar irradiation is in the range of $16.6-18.0 \mathrm{MJ} \mathrm{m}^{-2}$. The studied year shows an average value of $17.4 \mathrm{MJ} \mathrm{m}^{-2}$. In this zone, the minimum yearly DHW consumption fraction that the solar energy must supply is $60 \%$ (fulfilling a total consumption of the building lower than $5 \mathrm{~m}^{3}$ per day).

The building to be supplied with the solar plant lodges 215 inhabitants. Keeping in mind that the solar collector field has a total surface of $50 \mathrm{~m}^{2}$, the storage tank volume, applying Eq. (1), can be established between 2.5 to $9.0 \mathrm{~m}^{3}$.

In order to consider the incidence of the instantaneous water flow consumption profile (shown in Fig. 5) the one proposed by Viti [4] for the Spanish houses as standard is applied to the model, in place of the experimental constant value, the temperature at the tank outlet to consumption is left variable. The backup boiler is in charge of raising this temperature to the supply value of $60^{\circ} \mathrm{C}$ throughout the day.

In the case of the intermediate $V / A=0.06 \mathrm{~m}$, the annual solar fraction obtained is of $60.4 \%$, with a monthly value represented in Table 1 . The CTE establishes that the monthly solar fraction cannot be higher than $110 \%$ for a single month, neither can be $100 \%$ for three consecutive months (presumably to avoid overheating problems). As can be seen in Table 1, both months of July and August present an excess of energy that has to be dissipated.

In what follows the suitability of the size of the storage tank is studied, keeping constant the collector surface, $50 \mathrm{~m}^{2}$. These volumes correspond to a $V / A$ range from $0.03 \mathrm{~m}\left(V=1.5 \mathrm{~m}^{3}\right)$ to $0.18 \mathrm{~m}\left(V=9.0 \mathrm{~m}^{3}\right)$. The commercial storage tank sizes that have similar characteristics as the one of the experimental facility are: $1.5,2.0,2.5,3.0,3.5,4.0$ and $5.0 \mathrm{~m}^{3}$. Nevertheless, in order to achieve a better description of the solar fraction, the storage volume increment has been considered of $0.1 \mathrm{~m}^{3}$, between 1.5 and $5.0 \mathrm{~m}^{3}$ and the value of $9.0 \mathrm{~m}^{3}$ (as the largest recommended 

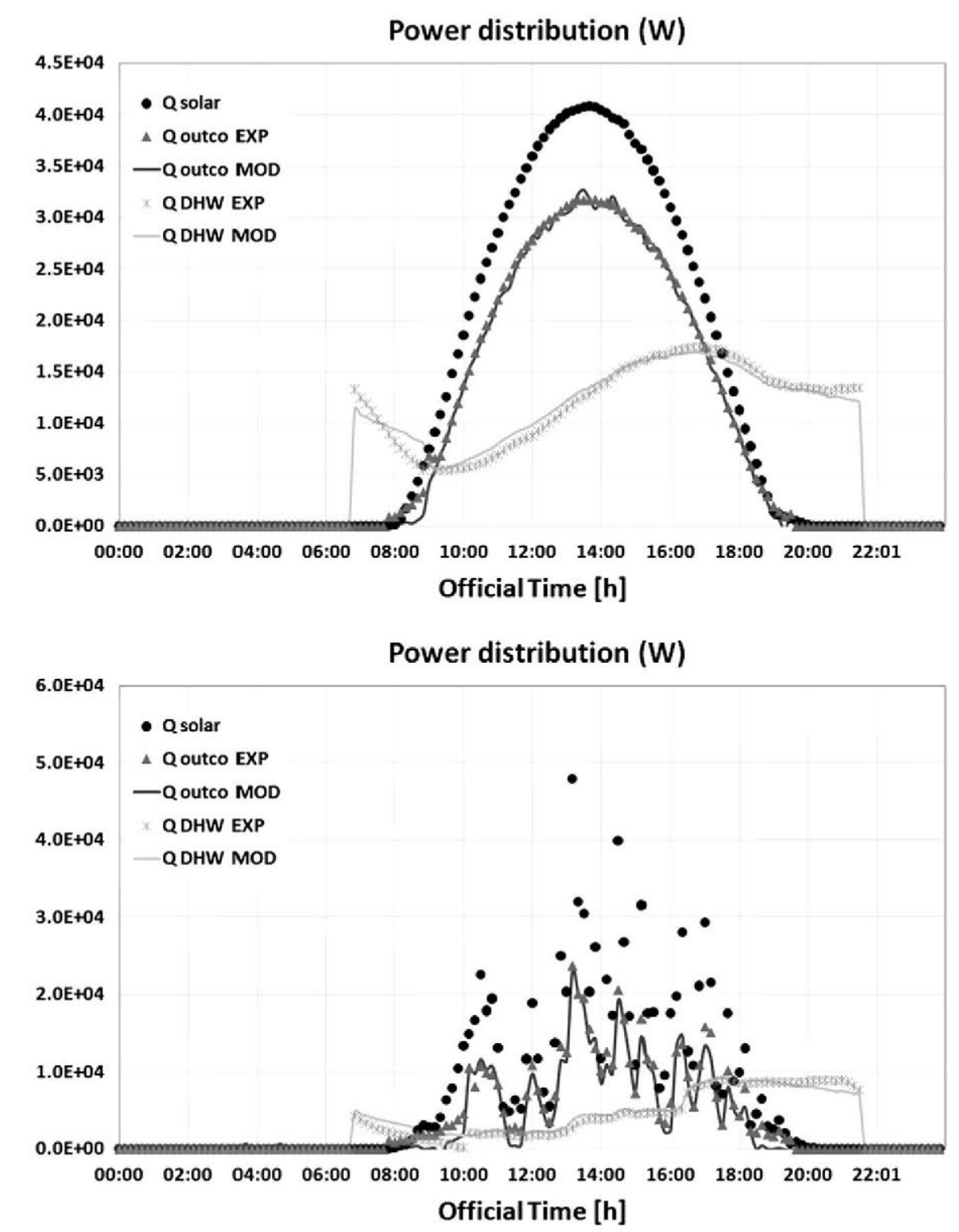

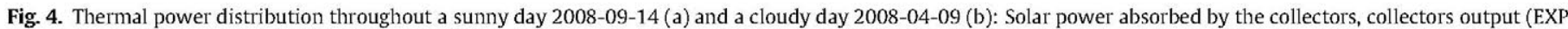
experimental, MOD modelled), and storage tank output employed in DHW production (Q DHW EXP, Q DHW MOD).

by the CTE). The storage tank diameter and height values have been interpolated from the commercial information.

Repeating the same calculations made for the experimental facility with a storage tank of $3 \mathrm{~m}^{3}(V / A=0.06 \mathrm{~m})$ with the different storage tanks volumes and keeping constant the collector field area, the following results have been obtained for the rest of the storage tank sizes, as Figs. 6 and 7 show.

Fig. 6 shows that the annual solar fraction changes from $56.8 \%$ to $61.5 \%$, reaching the CTE minimum value of $60.0 \%$ for $V \mid A=0.05 \mathrm{~m}$. Increasing the storage tank size does not yield a relevant increase in the annual solar fraction. For smaller values of $V / A$ the solar fraction decreases significantly. In order to explain this phenomenon, Fig. 7 shows that the monthly solar fraction exhibits a distinctive behaviour during the winter season: the solar fraction increases with increasing $V / A$, while during the summer season the solar fraction reaches a maximum value and then decreases. Both tendencies compensate each other to give the annual almost flat plateau curve. None of the storage tank sizes signifies a solution to overproduction in order to accomplish the CTE requirements.
Summer, spring and autumn months show a decrease in the solar fraction when $V / A$ increases between $0.07 \mathrm{~m}$ to $0.18 \mathrm{~m}$, Fig. 7 . This indicates that when solar radiation is higher the $V / A$ value shall be lower. Not only the solar fraction changes when storage tank size grows; the rest of the solar plant presents also different performances. Fig. 8 shows that when the storage tank volume increases, as the mean annual value of the working fluid temperature decreases, the thermal loss from heat exchanger diminishes. The heat exchanger is not insulated; for this reason, its thermal loss affects significantly the performance of the solar plant, especially for the smaller $V$. The mean values of the four working temperatures of the heat exchanger diminish with the increase of $V$. Meanwhile the own thermal heat loss from the storage tank increases with $V$, as the insulation thickness remains constant for the different volumes from the smallest value of $1.5 \mathrm{~m}^{3}(V / A=0.03 \mathrm{~m})$ to the highest one of $5 \mathrm{~m}^{3}(V / A=0.1 \mathrm{~m})$. That is the customary insulating condition in commercial storage tanks. For larger values of $V$, two storage tanks are needed, what translates into higher losses. The collector efficiency also increases as a direct consequence of the lower working 


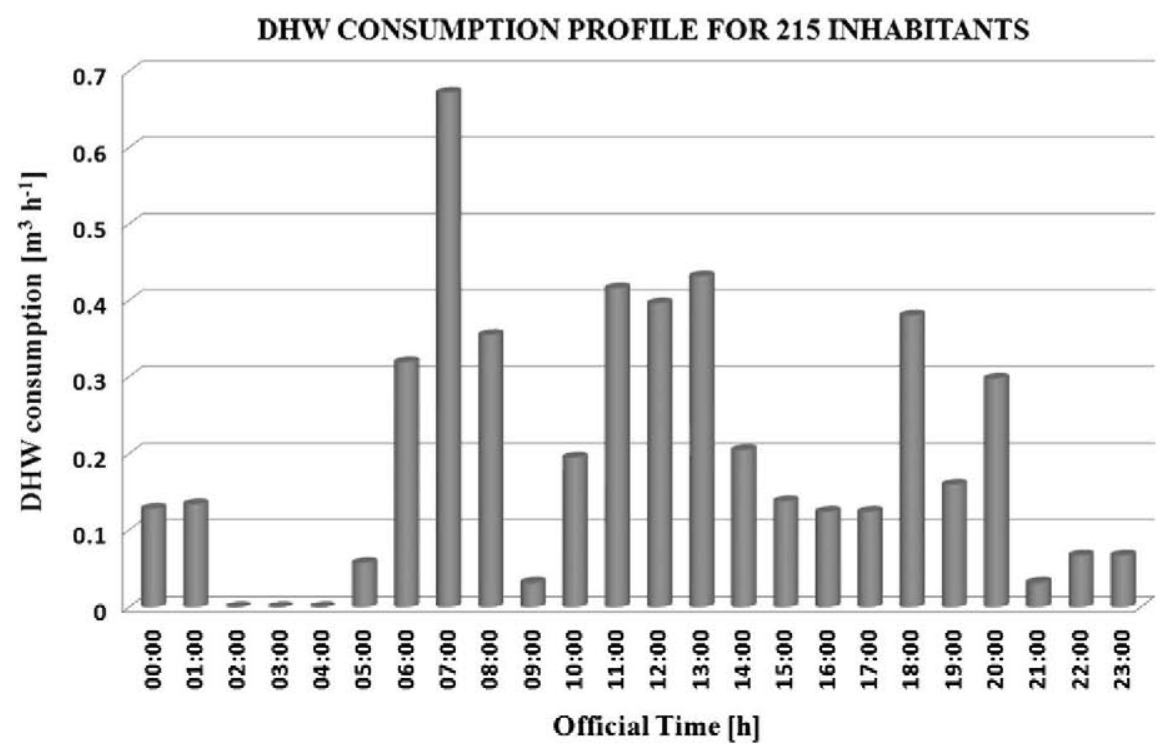

Fig. 5. Domestic hot water consumption profile for the 215 inhabitants [4].

Table 1

Solar fraction for the 215 inhabitants. Results obtained with the transient simulation program for $50 \mathrm{~m}^{2}$ of flat plate collectors and $V / A=0.06$. Results correspond to the experimental setup parameters.

\begin{tabular}{llll}
\hline Month & Solar fraction (\%) & Month & Solar fraction (\%) \\
\hline January & 40.8 & July & 118.6 \\
February & 53.5 & August & 111.1 \\
March & 58.8 & September & 77.2 \\
April & 67.1 & October & 60.2 \\
May & 73.6 & November & 43.9 \\
June & 89.2 & December & 38.4 \\
Annual & & $60.4 \%$ & \\
\hline
\end{tabular}

temperatures. The same happens with the solar plant efficiency for the smaller storage tank volumes, but from $V / A=0.06 \mathrm{~m}$ to $0.18 \mathrm{~m}$, the efficiency remains constant.
Typically, simplified methods for dimensioning solar facilities use the annual value of daily solar radiation, in Madrid this value is $17.4 \mathrm{MJ} \mathrm{m}^{-2}$. The chosen day of September has a daily solar radiation value of $17.9 \mathrm{MJ} \mathrm{m}^{-2}$, a similar value; this day could be thought as a representative day for the whole year in terms of radiation. This way, if the rest of the input variables needed are averaged throughout the year the results obtained could be expected to be similar to the annual ones previously obtained. Nevertheless, the optimum value of $V / A$ obtained under this framework with the average value of the rest of inputs for the same solar fraction value of $60.0 \%$ corresponds to $0.02 \mathrm{~m}$, a value smaller than the one obtained with the monthly along-the-year calculation.

This result highlights the relevance of monthly simulations in order to reach the suitable value of $V / A$, as it takes into consideration the variability of the weather that affects the solar facility performance.

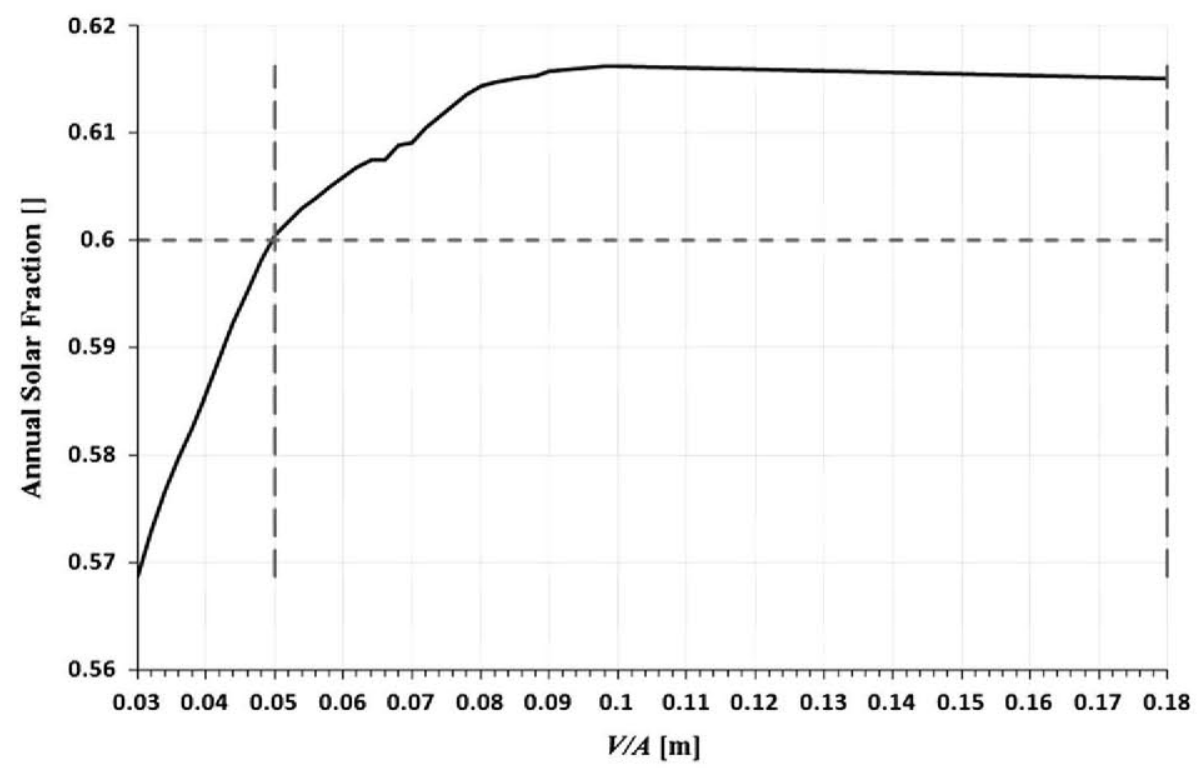

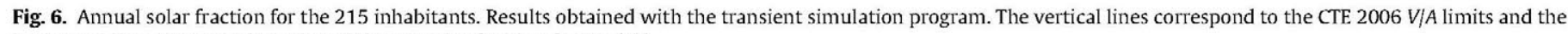
horizontal line corresponds to the minimum solar fraction for Madrid. 


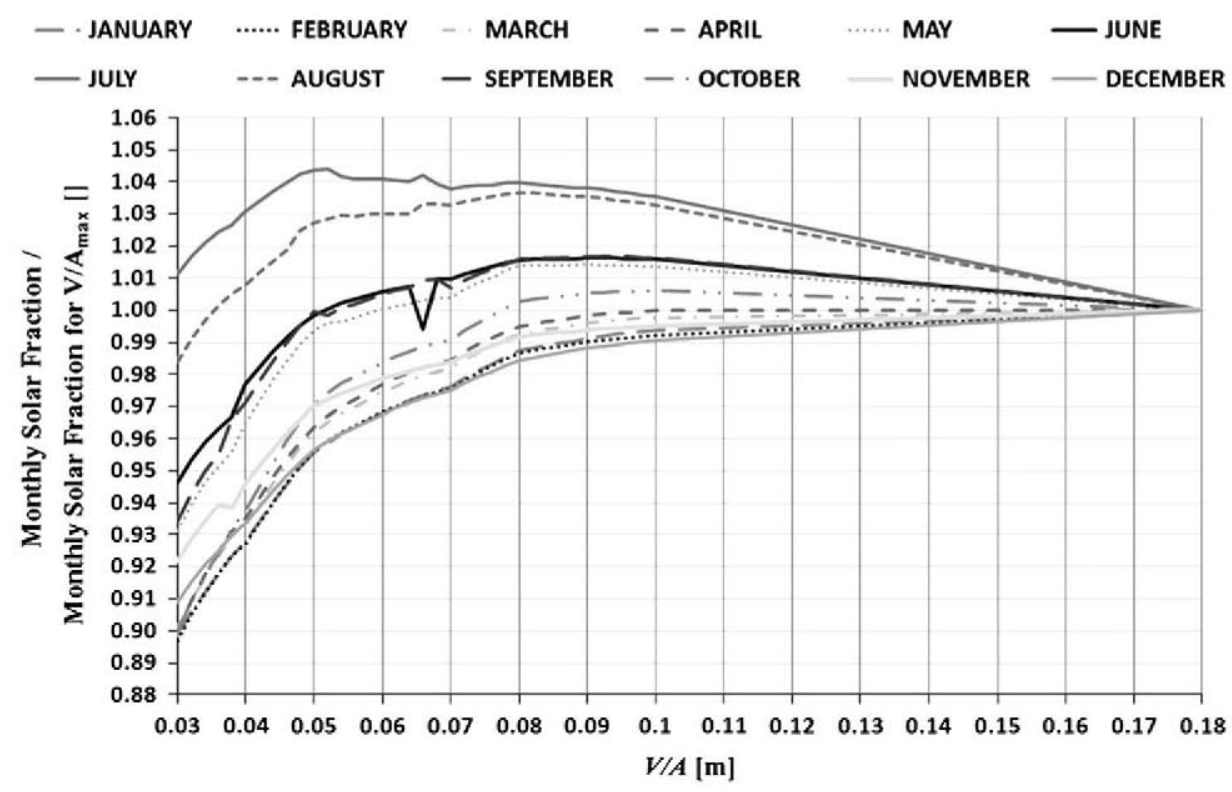

Fig. 7. Monthly solar fraction for the 215 inhabitants. Results are obtained with the transient simulation program. Results are normalized with the value for $V / A=0.18$.

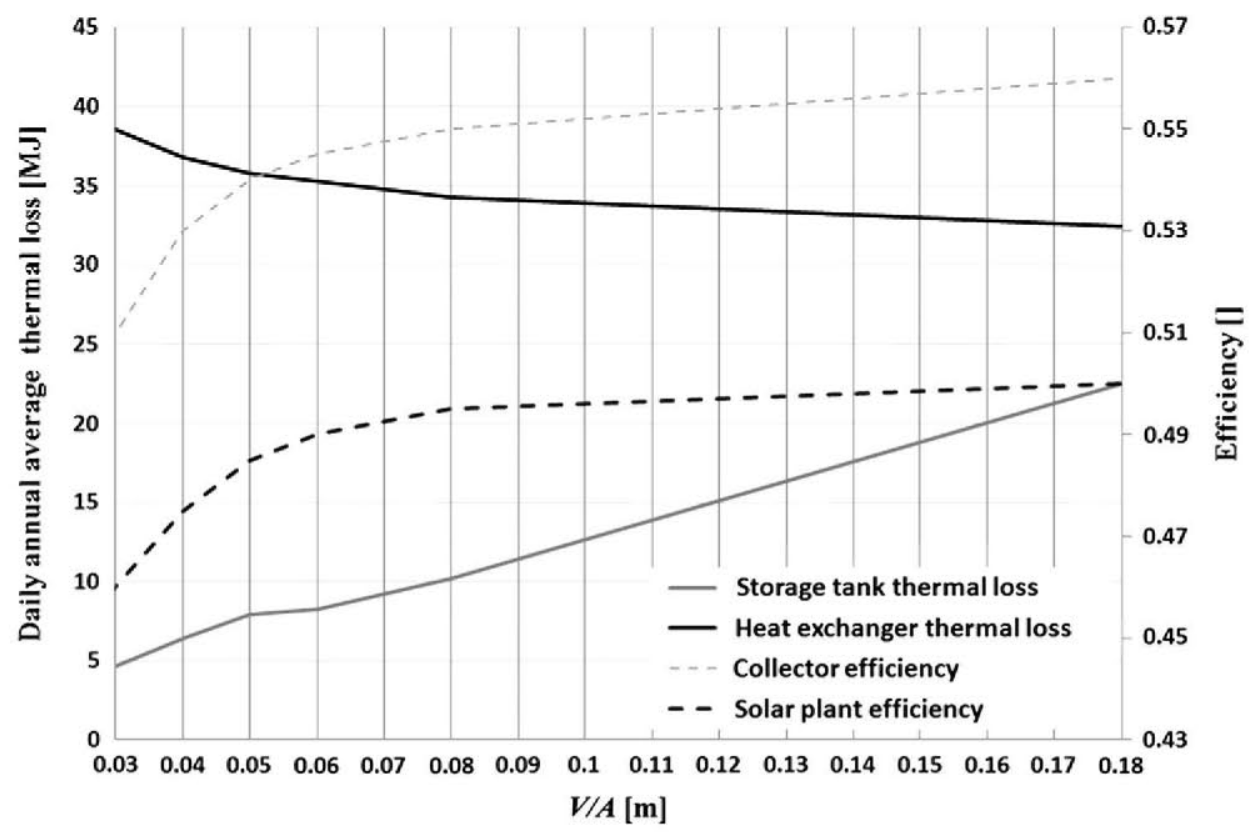

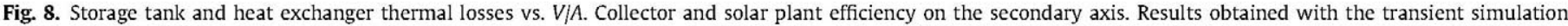
program for the daily annual average values.

A study of the natural gas savings seems advisable in order to illustrate which $V / A$ value between $0.05 \mathrm{~m}$ and $0.18 \mathrm{~m}$ is optimum from the consumption point of view. This would coincide with the $\mathrm{CO}_{2}$ emission saving. $\mathrm{CO}_{2}$ emission saving is evaluated considering that $0.22 \mathrm{~kg} / \mathrm{kW}$ h are emitted when natural gas is used as fuel in the DHW backup system [52]. As seen in Fig. 9, the maximum saving happens for a $V / A=0.08 \mathrm{~m}$, keeping constant for larger values of this parameter, being this value the minimum size in terms of $\mathrm{CO}_{2}$ and natural gas savings. This is a higher value than the $0.05 \mathrm{~m}$ obtained above for minimum CTE solar fraction; but, in any case, this volume is smaller than the maximum recommended in the CTE of $0.18 \mathrm{~m}$. Table 2 shows the annual and monthly solar fraction values for $V / A=0.08 \mathrm{~m}$, as can be seen the obtained values are higher than for $V / A=0.06 \mathrm{~m}$ for each month and consequently for the annual value. The overproduction problem is increased but not in a substantial amount.

Table 3 presents the payback period of a solar plant equipped with $50 \mathrm{~m}^{2}$ of flat plate solar collectors $\left(340 € \mathrm{~m}^{-2}\right)$ and a vitrified steel storage tank with heat exchanger coil $\left(3.0 \mathrm{k}^{-3} \mathrm{~m}^{-3}\right)$. The payback period is dependent on the storage tank volume; as smaller is the storage tank, the sooner the initial cost is recovered from natural gas savings. This reinforces that the optimal value of $V / A$ should be the minimum given in CTE. This has been obtained with a natural gas price of $0.03752 € \mathrm{~kW} \mathrm{~h}^{-1}$ plus a fixed cost of 


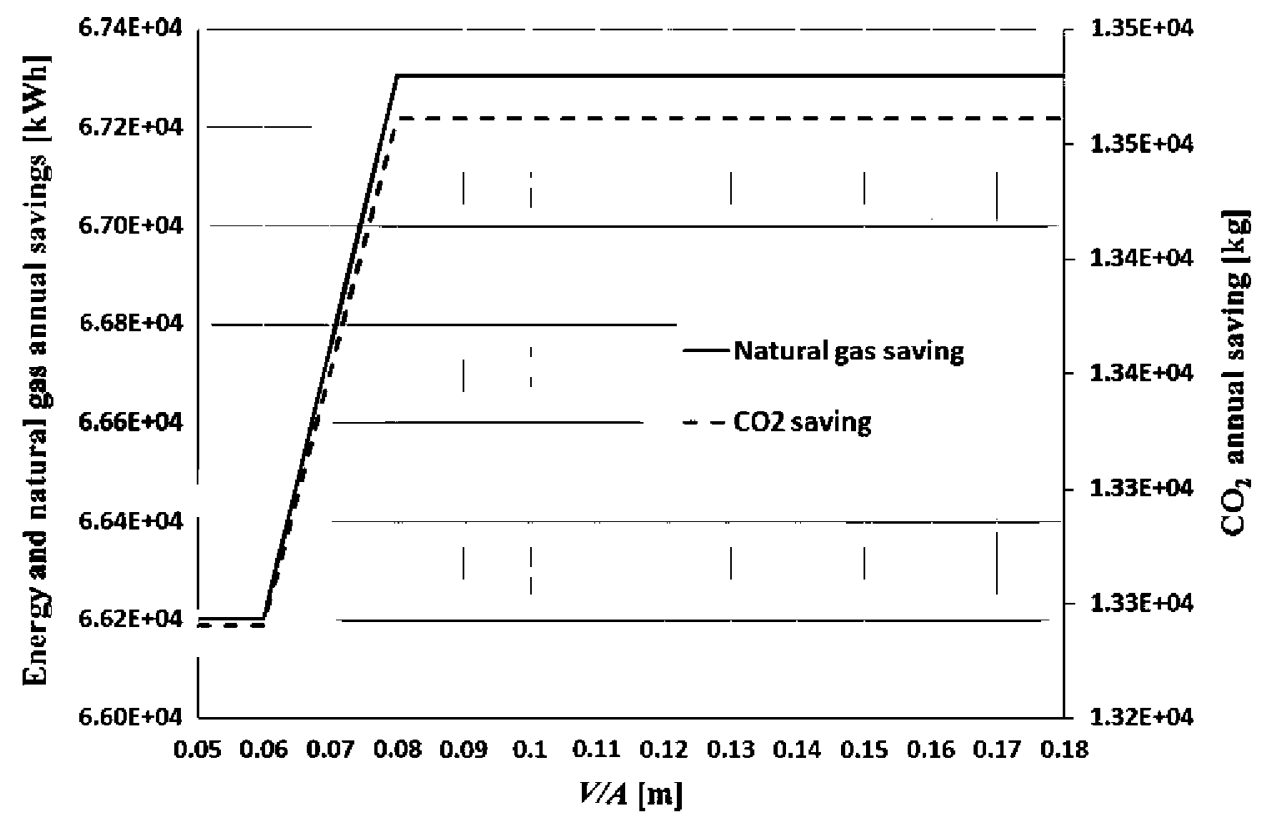

Fig. 9. Natural gas saving vs. V/A. $\mathrm{CO}_{2}$ saving (secondary axis) vs. V/A for the annual values.

Table 2

Solar fraction for the 215 inhabitants. Results obtained with the transient simulation program for $50 \mathrm{~m}^{2}$ of flat plate collectors and $V / A=0.08$. Results correspond to the experimental setup parameters.

\begin{tabular}{llll}
\hline Month & Solar fraction (\%) & Month & Solar fraction (\%) \\
\hline January & 41.6 & July & 121.7 \\
February & 54.7 & August & 113.5 \\
March & 59.7 & September & 78.8 \\
April & 68.2 & October & 61.9 \\
May & 75.1 & November & 44.5 \\
June & 91.1 & December & 39.0 \\
Annual & & $61.4 \%$ & \\
\hline
\end{tabular}

Table 3

Payback period for a solar plant with $50 \mathrm{~m}^{2}$ collector area and different storage tank volumes.

\begin{tabular}{lll}
\hline Storage tank volume $\left(\mathrm{m}^{3}\right)$ & $V / A(\mathrm{~m})$ & Solar plant payback (years) \\
\hline 2.5 & 0.05 & 18.6 \\
3.0 & 0.06 & 18.6 \\
4.0 & 0.08 & 19.6 \\
9.0 & 0.18 & 25.1 \\
\hline
\end{tabular}

$43.66 €$ month $^{-1}$ (Spanish gas prices for year 2008). The $V / A$ value

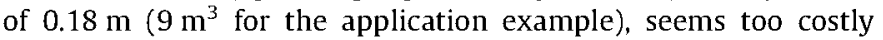
and bulky to be implemented in a domestic solar plant of this kind.

\section{Conclusions}

The study performed reveals that the storage tank size is relevant in the solar plant performance. This is especially relevant for values of $V / A<0.05 \mathrm{~m}\left(2.5 \mathrm{~m}^{3}\right.$ for a solar plant with a collector area of $50 \mathrm{~m}^{2}$ ) that may be considered as a critical design condition, due to the degradation of the solar plant performances for lower values of this parameter. Moreover, this value is the minimum that provides the $60 \%$ of annual solar fraction prescribed by the Spanish regulation CTE 2006 for the climatic zone of Madrid.

Its cost represents an important part of the procurement budget. For example, dimensioning the storage tank with the above mentioned critical value of $V / A$, it amounts $23.4 \%$, being the collector field the $37.8 \%$, of the total budget.

The cost of the storage tank can match the cost of the solar collectors field, $15,000 €$ for $50 \mathrm{~m}^{2}$ of absorber surface, but if the storage tank is oversized it could even double this quantity, probably requiring the use of two commercial tanks.

Oversizing the storage tank volume above the value of $0.08 \mathrm{~m}$ for $V / A$, does not mean getting a significantly higher solar fraction for DHW consumption, neither to achieve better solar plant efficiency.

Using an annual average value of the environmental variables, the critical $V / A$ value obtained in a single "average" day simulation is significantly smaller than $0.05 \mathrm{~m}$, the value obtained with the monthly simulation.

Regarding the natural gas consumption and $\mathrm{CO}_{2}$ emission savings, the optimal storage tank results in a higher value than the critical one. This means $V / A=0.08 \mathrm{~m}$, i.e. $4.0 \mathrm{~m}^{3}$ for the solar plant considered, but in any case, this volume is much smaller than the maximum of $V / A=0.18 \mathrm{~m}$, i.e. $9 \mathrm{~m}^{3}$ recommended by CTE, and higher than the critical value. For this reason, the practical value in terms of payback period has to be coincident with the so-called critical value, as the minimum value that matches the CTE restrictions.

\section{Acknowledgements}

This work has been partially funded by the Spanish government research Grant M.C.T. CLIMABCAR Project DPI 2003-01567, MINICON Project (FIT 0204-2004-68 and FIT 020100-2003-233) and SACSCC Project (ENE 2007-63965). Their contribution is greatly appreciated. We would like also to express a special acknowledgement to the laboratory technicians: Mr. Manuel Santos and $\mathrm{Mr}$. Carlos Cobos for their help with the solar plant setup and maintenance.

\section{References}

[1] Meyer JP, Tshimankinda M. Domestic hot-water consumption in South African apartments. Energy 1998;23:61-6.

[2] Rodríguez Hidalgo MC, Rodríguez Aumente PA, Izquierdo Millán M, Lecuona Neumann A, Nogueira Goriba JI, Alfaro Martínez JA. Combined DHW and 
air-conditioning solar applications a thermo-economic analysis for Madrid region. In: Perugia: proceedings, 2006. 61 Congresso nazionale ATI. Solar heating and cooling international session. p. 215-20.

[3] Rodríguez Hidalgo MC, Rodríguez Aumente PA, Izquierdo Millän M, Salgado Mangual RA, Nogueira Goriba JI, Alfaro Martínez JA. Solar facilities elements selection for a combined use of DHW and climatizing. In: Aghia Pelagia Creta Grecia: proceedings, 2006. 19th international conference of efficiency, cost, optimization, simulation and environmental impact of energy systems. p. $1539-46$.

[4] Viti, A. DTIE 1.01: preparación de agua caliente para usos sanitarios. [ed.] ATECYR. s.l.: EL INSTALADOR, Madrid, Spain; 1994.

[5] Ndoye B, Sarr M. Analysis of domestic hot water energy consumption in large buildings under standard conditions in Senegal. Build Environ 2008;43:1216-24.

[6] Papakostas KT, Papageorgiou NE, Sotiropoulos BA. Residential hot water use patterns in Greece. Solar Energy 1995;54:369-74

[7] Wolf D, Tamir A, Kudish AI. A central solar domestic hot water system. Performance and economic analysis. Energy 1980;5:191-205.

[8] Courtney RG. A computer study of solar water heating. Build Environ $1977 ; 12: 73-80$.

[9] Perlman M, Mills BE. Development of residential hot water use patterns. ASHRAE Trans 1985;91(Part 2):657-79.

[10] Directive 2002/91/EC of the European Parliament and the Council of 16 December 2002 on the energy performance of buildings.

[11] Real Decreto 314/2006. Código Técnico de la Edificación. Boletín Oficial del Estado, BOE 28/03/06, Madrid, Spain; 2006.

[12] UNI TS 11300. Prestazioni energetiche degli edifici UNI Ente Nazionale Italiano di Unificazione, Rome, Italy; 2008.

[13] Tanton DM, Cohen RR, Probert SD. Improving the effectiveness of a domestic central heating boiler by the use of heat storage. Appl Energy 1987;27:53-82.

[14] EN-12975. Sistemas solares térmicos y componentes. Captadores solares. Norma, Madrid: AENOR; 2006.

[15] ENV-12977. Sistemas solares térmicos y sus componentes. Instalaciones a medida. Norma, Madrid: AENOR; 2002.

[16] Wolf D, Sembira AN, Kudish AI. Dynamic simulation and parametric sensitivity studies on a central solar domestic hot water system. Energy 1984;9:169-81.

[17] Spirkl W. Dynamic solar domestic hot water testing. J Solar Energy Eng Trans ASME 1990;112:98-101.

[18] Fanney AH, Klein SA. Thermal performance comparisons for solar hot water systems subjected to various collector and heat exchanger flow rates. Solar Energy 1988;40:1-11.

[19] Gutierrez G, Hincapie F, Duffie JA, Beckman WA. Simulation of forced circulation water heaters; effects of auxiliary energy supply, load type and storage capacity. Solar Energy 1974;15:287-98.

[20] Panteliou S, Dentsoras A, Daskalopoulos E. Use of expert systems for the selection and the design of solar domestic hot water systems. Solar Energy $1996 ; 57: 1-8$

[21] Buckles WE, Klein SA. Analysis of solar domestic hot water heaters. Solar Energy $1980 ; 25: 417-24$

[22] Kenna JP. A parametric study of open loop solar heating systems-I. Solar Energy 1984;32:687-705.

[23] Kenna JP. A parametric study of closed loop solar heating systems Il. Solar Energy $1984 ; 32: 707-23$.

[24] Gadsden S, Rylatt M, Lomas K. Putting solar energy on the urban map: a new GIS-based approach for dwellings. Solar Energy 2003;74:397-407.

[25] Hobbi A, Siddiqui K. Optimal design of a forced circulation solar water heating system for a residential unit in cold climate using TRNSYS. Solar Energy $2009 ; 83: 700-14$

[26] Fraisse $G$ et al. Comparative study of various optimization criteria for SDHWS and a suggestion for a new global evaluation. Solar Energy 2009;83:232-48.

[27] Chow TT et al. Potential application of a centralized solar water heating system for a high rise residential building in Hong Kong. Appl Energy 2006;83:42-54.

[28] Lima JBA, Prado RTA, Taborianski VM. Optimization of tank and flat plate collector of solar water heating system for single family households to assure economic efficiency through the TRNSYS program. Renew Energy 2006;31:1581-95.

[29] Brinkworth B]. Selection of design parameters for closed circuit forced circulation solar heating systems. Solar Energy $1975 ; 17: 331-3$.

[30] Brinkworth B]. Solar DHW system performance correlation revisited. Solar Energy 2001;71:377-87.

[31] Pedersen PV. System design optimization for large building integrated solar heating systems for domestic hot water. Solar Energy 1993;50:267-73.

[32] Bojic M, Kalogirou SA, Petronijevic K. Simulation of solar domestic water heating system using a time marching model. Renew Energy 2002;27:441-52.

[33] Cardinale N, Piccininni F, Stefanizzi P. Economic optimization of low flow solar domestic hot water plants. Renew Energy 2003;28:1899-914.

[34] Spirkl W, Muschaweck J. General model for testing solar domestic hot water systems. Solar Energy Mater Solar Cells 1992;28:93-102.

[35] Krause $\mathrm{M}$ et al. Investigations on optimizing large solar thermal systems. Solar Energy 2002;73:217-25

[36] Kalogirou SA. Long-term performance prediction of forced circulation solar domestic water heating system using artificial neural networks. Appl Energy 2000;66:63-74.

[37] Beckman WA, Klein SA, Duffie JA. Solar heating design by the f-Chart method. New York: Wiley-Interscience; 1977.

[38] Klein SA, Beckman WA, Duffie JA. A design procedure for solar heating systems. Solar Energy 1976;18:113-27.

[39] Ghaddar NK. Stratified storage tank influence on performance of solar water heating system tested in Beirut. Renew Energy 1994;4:911-25.

[40] Klein SA et al. A method of simulation of solar processes and its application. Solar Energy 1975;17:29-37.

[41] Andersen E, Furbo S. Theoretical variations of the thermal performance of different solar collectors and solar combisystems as function of the varying yearly weather conditions in Denmark. Solar Energy 2009;83:552-65.

[42] Rodríguez Hidalgo MC, Rodríguez Aumente P, Izquierdo Millán M, Lecuona Neumann A, Salgado Mangual R. Energy and carbon emission savings in Spanish housing air-conditioning using solar driven absorption system. Appl Therm Eng 2008;28:1734-44.

[43] Rodríguez-Hidalgo MC, Rodriguez-Aumente PA, Lecuona A, Gutierrez-Urueta GL, Ventas R. Flat plate thermal collector efficiency: transient behavior under working conditions. Part I: model description and experimental validation. Appl Therm Eng 2011;31:2394-404.

[44] Aubinet M. Longwave sky radiation parametrizations. Solar Energy 1994:53:147-54

[45] Vine E, Diamond R, Szydlowski R. Domestic hot water consumption in four low-income apartment buildings. Energy 1987;12:459-67.

46] Rodriguez-Hidalgo MC. Estudio en régimen transitorio de plantas solares térmicas de propósito múltiple. Aplicación al diseño de instalaciones concebidas para agua caliente sanitaria. PhD thesis, Universidad Carlos III de Madrid, Spain; 2010. <http://hdl.handle.net/10016/7494>.

[47] Klein SA, Alvarado F. Engineering equation solver, v. 8.186-3D, F-Chart Software, Middleton, WI; 1999.

[48] Rodriguez-Hidalgo MC, Rodriguez-Aumente PA, Lecuona A, Gutierrez-Urueta GL, Ventas R. Flat plate thermal collector efficiency: transient behavior under working conditions. Part II: model application and design contributions. App Therm Eng 2011;31:2385-93.

[49] Duffie JA, Beckman WA. Solar engineering thermal processes. USA: John Wiley and Sons: 2006.

[50] Rodriguez-Hidalgo MC, Rodriguez-Aumente PA, Lecuona A, Nogueira J Instantaneous performance of solar collectors for domestic hot water heating and cooling applications. Energy Build, in press. doi:10.1016 i.enbuild.2011.10.060

[51] Barron RF. Effect of heat transfer from ambient on cryogenic heat exchanger performance. Adv Cryogen Eng 1984;29:265-72.

[52] Energy, transport and environment indicators. Eurostat Pocket Books. 2009 Edition. ISSN $1725-4566$ 